Arciniegas Martínez, Ana Teresa.

Profesora Asociada e Investigadora Programa de Artes Audiovisuales.

Universidad Autónoma de Bucaramanga-Colombia.

\title{
Documental interactivo para la difusión de los saberes y quehaceres del patrimonio cultural.
}

\section{Interactive documentary for the dissemination of the knowledge and tasks of cultural heritage.}

\author{
TIPO DE TRABAJO: \\ Comunicación. \\ PALABRAS CLAVE: \\ Documental interactivo, hipermedia educativo, patrimonio cultural. \\ KEY WORDS: \\ Interactive documentary, educational hypermedia, cultural heritage.
}

\section{RESUMEN.}

La comunicación es resultado de una investigación realizada en la Universidad Autónoma de Bucaramanga sobre los saberes y quehaceres tradicionales que hacen parte del patrimonio cultural inmaterial del oriente colombiano. El resultado es un documental interactivo, hipermedia educativo, que tiene como fin divulgar dos oficios tradicionales: la talla en piedra y el tejido de artesanal de la planta del fique. Los jóvenes artesanos aprenden el quehacer de los mayores, quienes han trabajado toda su vida en ello y transmiten su conocimiento a las nuevas generaciones. Sin embargo, los artesanos se enfrentan a una disyuntiva por un lado de continuar con la preservación del oficio conlleva riesgos en su salud y repercusiones ambientales dentro de su contexto de trabajo. La investigación se divide en dos partes, en la primera se determinó cuales eran los oficios tradicionales en la zona mediante trabajo de campo; en la segunda parte de la investigación, y en relación a la tipología de proyecto aplicado, se realizo una obra audiovisual interactiva que tiene un objetivo didáctico y divulgativo. En el diseño y aplicación de la obra se han utilizado algunos recurso del arte digital como documental interactivo, imágenes 360 , infografías y narración no lineal.

\section{ABSTRACT}

The communication is the result of research carried out at the Autonomous University of Bucaramanga on the traditional knowledge and chores that are part of the intangible cultural heritage of eastern Colombia. The result is an interactive documentary, hypermedia educational, whose purpose is to divulge two traditional trades: carving in stone and the handmade fabric of the plant fique. The young craftsmen learn the work of the elders, who have worked all their lives in it and transmit their knowledge to the new generations. However, artisans face a problem on the one hand to continue with the preservation of the trade carries risks in their health and environmental repercussions within their working context. The research is divided into two parts, the first one determined the traditional trades in the area through field work; In the second part of the research, and in relation to the typology of applied project, an interactive audiovisual work was carried out that has a didactic and informative objective. Some digital art resources have been used in the design and application of the work, such as interactive documentary, 360 images, infographics and non-linear narrative. 


\section{CONTENIDO.}

\section{INTRODUCCIÓN}

El uso de las tecnologías de la información y la comunicación TIC en la difusión digital y documentación del patrimonio cultural, sigue siendo una cuestión pendiente en Colombia. De ahí que resulte necesario el desarrollo de estrategias audiovisuales que visibilicen los oficios tradicionales del oriente colombiano, como parte de la divulgación del patrimonio cultural inmaterial. Las tecnologías de la información permiten mostrar los relatos en distintas unidades formales y de sentido, grabar la historia, aislar los elementos espaciales, convirtiendo el espacio y el tiempo en medios de desplazamiento, otorgando al espectador la posibilidad de acción y toma de decisiones, potenciando su creatividad, invitando a que el espectador participe activamente.

Se denomina hipermedia audiovisual a las narraciones realizadas mediante hipertextos, es decir compuestas por un conjunto de fragmentos de texto relacionados entre sí por enlaces. Los hipermedia se caracterizan por no tener un camino establecido por el autor, y dejan al espectador la capacidad de elegir entre varias rutas posibles, en ocasiones no hay un comienzo establecido y casi nunca se tiene un final. Los audiovisuales hipertextuales requieren de un lector activo, los roles de emisor y receptor pueden ser intercambiables, los contenidos pueden ser abiertos y dependientes de las elecciones del usuario. En síntesis, en el esquema narrativo hipertextual nociones comocentro, margen y secuencialidad son sustituidas por la conceptos como multilinealidad, nodos, nexos y redes, que se asemejan a las figuras rizomáticas planteadas por Deleuze \& Guattari (1985).

En el proyecto de investigación se realizó el inventario de los saberes y quehaceres patrimoniales culturales existentes en 2 municipios del departamento de Santander: Curití y Villanueva, ubicados en la zona del Cañón del Chicamocha, al oriente de Colombia. La investigación dio como resultado el diseño y desarrollo de un hipermedia audiovisual que muestra el oficio tradicional de la talla en piedra y el oficio artesanal del fique. La vigencia de estos oficios a en la región evidencian la continuidad de los haceres y saberes ancestrales que dan identidad regional a las comunidades. La permanencia de estos oficios promueven una relación entre el pasado y el presente, lo que demuestra que el Patrimonio inmaterial de una comunidad es parte decisiva en el desarrollo de la comunidad.

\section{OBJETIVOS.}

2.1 Objetivo general: realizar el inventario de los oficios, saberes y quehaceres patrimoniales culturales existentes en dos municipios de la región de Santander, dando como resultado el diseño y desarrollo de un hipermedia educativo que promueve la difusión digital de las tradiciones patrimoniales.

2.2 Objetivos específicos:

2.2.1 Identificar los oficios, saberes y quehaceres patrimoniales culturales propios de cada comunidad, en los municipios objeto de estudio.

2.2.2 Evaluar y registrar cada oficio patrimonial cultural de la región.

2.2.3 Realizar un relato hipermedial de consulta permanente en línea.

2.2.4 Realizar un trabajo de reforzamiento de la identidad en las comunidades de los municipios estudiados.

2.2.5 Contribuir al conocimiento y preservación del patrimonio cultural colombiano.

\section{METODOLOGÍA.}

El proyecto se abordó de manera secuencial en cada uno de los municipios, desde una perspectiva cuantitativa, ceñido a las normas establecidas por la UNESCO para el análisis de este tipo de trabajos.

3.1 Primera etapa: base de datos y digitalización de cada uno de los oficios tradicionales, haceres, saberes y prácticas de acuerdo a las normas establecidas por la UNESCO para el análisis de este tipo de trabajos, a saber: identificación, inventario, evaluación, y registro. Para cada uno de los oficios tradicionales se realizó una revisión de fuentes y estado del arte, validación del inventario patrimonial y cultural existente, trabajo exploratorio de campo, documentación y evaluación.

3.2 Segunda etapa: realización del hipermedia educativo, comunicación y divulgación de resultados obtenidos en cada municipio en tres subetapas propias del quehacer audiovisual: pre-producción (escritura del guion hipermedia y técnico, plan de producción y de grabación); producción (rodaje en cada uno de los seis municipios; y post -producción (edición no lineal, programación, diseño gráfico, colorización y sonorización).

Durante las dos etapas se tuvieron en cuenta la integración y participación de las comunidades en la identificación del patrimonio local, así como la protección y conservación del patrimonio natural de la zona.

\section{DESARROLLO.}

Las narraciones audiovisuales están cambiando, el uso de internet, el empleo de nuevas tecnologías y la oferta de productos audiovisuales en múltiples dispositivos han modificado la forma de realizar y exhibir los audiovisuales. Como señala Scolari (2013) las 
nuevas formas de comunicación digital han hecho que las narraciones audiovisuales evolucionen hasta relatos de base intertextual, red de textos, videos, audios, etc. En consecuencia, en los proyectos transmedia el guion será algunas veces rizomático y los contenidos tendrán esa dirección perpendicular que permitirá que los usuarios puedan moverse entre un video, una pista de audio, una infografía, un hipervínculo, una galería fotográfica, una animación, y otras posibilidades. El guion en estos proyectos será una escaleta no lineal que abarca los conceptos principales a abordar en el documental interactivo que se resume en una especie de cartografía creativa.

El término Narraciones Transmedia fue acuñado por Henry Jenkins, profesor del MIT, en el 2003, en la revista Review del Massachusetts Institute of Technology MIT, el transmedia, en su expresión más básica, significa historias a través de medios. Al respecto Carlos Scolari (2013), específicamente sobre el documental transmedia, argumenta que va más allá y lleva sus contenidos a otros medios y plataformas, buscando siempre la complicidad. El documental transmedia necesariamente distribuye su contenido en diferentes plataformas digitales.

La plataforma utilizada para exhibir los proyectos transmedia es Internet. Los audiovisuales alojados en la Web son de consulta permanente y están a disposición del usuario sin restricción de tiempo. Internet proporciona a los documentalistas herramientas propicias para la creación de proyectos que emplean narrativas no lineales. Una de las consecuencias del cambio en el audiovisual contemporáneo es el rol que adquiere el espectador, quien pasa de tener un rol pasivo a uno activo. El espectador ahora se vuelve más un usuario del que se requiere una participación constante en las propuestas narrativas. Asimismo, el rol del realizador de modifica Giannetti (2002) plantea que la conectividad, la hipertextualidad y la interactividad son modos que están vinculados a la autoría descentralizada y a la participación colectiva.

En consecuencia, los proyectos transmedia se convierten en una herramienta eficaz en los procesos educativos, porque además de ser una experiencia lúdica y entretenida, tiene una intención marcadamente pedagógica y es ante todo una experiencia didáctica. Este tipo de formatos tienen la posibilidad de ser más llamativos para las audiencias jóvenes, debido a que las nuevas generaciones precisan interactuar de manera constante con contenidos, pues una única pantalla, les puede resultar en ocasiones aburrido.

Por otro lado, la producción en Colombia de audiovisuales transmedia, desde el año 2012, ha sido creciente y hay un incipiente pero prolífico desarrollo tanto en las iniciativas de producción, como de exhibición y de formación en el área. La mayoría de las obras no lineales tiene una característica común y es la intención por preservar la memoria y salvaguardar el patrimonio del país, son pocos los audiovisuales transmedia que han abordado temas patrimoniales. La mayoría de los esfuerzos se concentran en el documental de denuncia y son de modalidad expositiva.

Sin embargo el género documental en Colombia no ha sido ampliamente difundido en el país debido a dos razones principales: primero, porque la exhibición y distribución del documental no ha sido una prioridad para la industria cinematográfica colombiana y, segundo, porque dentro del sistema de preferencias del público se anteponen los filmes de ficción a los documentales.

Ante estas dos dificultades, los audiovisuales interactivos se convierten en una solución viable, por un lado porque la exhibición y distribución se hace a través de Internet, deslegitimando la idea de industria porque el espectador no tiene restricciones de acceso. Por otro lado, las narraciones no lineales son una opción narrativa apetecida por las nuevas generaciones, es decir, tiene sus propios espectadores.

En este marco, surge el proyecto "Difusión digital de las manifestaciones asociadas a los saberes y quehaceres culturales en Santander. Hipermedia educativo para la apropiación de los oficios tradicionales en la región", como una posibilidad a través del uso de las TIC para la promoción, protección y divulgación de los oficios tradicionales patrimoniales, dirigida fundamentalmente a nueva audiencias. La utilización de las tecnologías de la información y la comunicación (TIC) han establecido una forma diferente de configurar los espacios del conocimiento, transformando las prácticas de la pedagogía, permitiendo así conexiones transversales con el saber. El flujo de información, la incesante transformación de las tecnologías de la comunicación y el acceso irrestricto al conocimiento se han convertido en una constante en los nuevos medios de comunicación. A las implicaciones culturales de las nuevas tecnologías de la información y la comunicación en la sociedad se les ha denominado con el término cibercultura Levy (2007) y los estudios de esa nueva relación que se establece con el saber, se han configurado desde diversas corrientes que van desde la cultura visual, las implementaciones tecnológicas, hasta los métodos de aprendizaje en estas nuevas plataformas. La iniciativa de relacionar las TIC con la difusión del patrimonio cultural responde a la necesidad de contar con medios de comunicación y divulgación que promuevan la conservación y la puesta en valor del patrimonio cultural.

La relación entre lo patrimonial y lo tecnológico será esa conjunción de la naturaleza y de la cultura, de lo salvaje y del artificio. La posible definición que ha propuesto Maffesoli (2012) de la posmodernidad como una sinergia de lo arcaico y del desarrollo tecnológico, será al unir lo arcaico con la tecnología que el imaginario se renueva con la sensibilidad que todos compartimos. Es ahí también, donde entrará la memoria colectiva, una memoria patrimonial, donde se condensan, como por sedimentaciones, todas las expresiones micro o macroscópicas que se inscriben en una comunidad particular. El dispositivo propuesto de un hipermedia audiovisual plantea una dicotomía entre el progreso y la memoria, una unión entre lo arcaico con lo tecnológico, sin llegar a afirmar que la herencia cultural de una sociedad tenga que ser arcaica; al contrario no hay nada más actual y más vivo en toda comunidad que 
la afirmación y la identidad con su herencia y su pasado. El acto de la destrucción es contrario al video, porque las imágenes son inmortales, lo serial, lo fotográfico, la mortalidad en la imagen, habla de la eternidad, de la perdurabilidad, el dispositivo audiovisual posibilita esa eternidad, esa memoria. En este sentido, cobra aún más vigencia e importancia la utilización de los medios tecnológicos en la preservación del Patrimonio Cultural.

Otro de los grandes retos los trabajos elaborados entorno a la digitalización patrimonial es el de llegar a nuevos públicos, en ese sentido el uso de herramientas web 2.0, de recursos en línea y de los canales de comunicación como las redes sociales posibilitan el contacto directo de personas que habitualmente están en contacto permanente con las TIC y con un sector de la población relativamente joven que es el que está en mayor contacto con ellas y en menor contacto con los temas relacionados al patrimonio. Supliendo así en parte la necesidad de llegar a las nuevas generaciones, para que conozcan y otorguen valor a lo heredado. En ese sentido el lenguaje empleado tanto por el multimedia, el hipermedia y en nuestro caso particular el documental interactivo les es cercano y les resulta familiar. Los recursos digitales se convierten en un banco de herramientas en línea para que los usuarios las utilicen a su conveniencia, los dispositivos hipermediales juegan así el rol de mediador entre las personas y los contenidos patrimoniales.

\section{RESULTADOS.}

5.1 Material audiovisual de consulta permanente, de libre acceso para la comunidad académica que promueve la salvaguarda y puesta en valor del patrimonio inmaterial. Material de consulta que permita formular nuevas investigaciones.

5.2 Ampliación de la distribución del hipermedia o transmedia, ampliando el número de beneficiarios directos e indirectos que puedan acceder a él. Distribución en las alcaldías, casas de cultura, museos, bibliotecas, universidades, colegios y en entes que estén relacionados con actividades culturales.

5.3 Apertura de portal web educativo de consulta de acceso libre en internet del hipermedia educativo sobre los oficios tradicionales de Santander.

5.4 Consolidación de los productos hipermedia educativos como unidades de aprendizaje digitales que promuevan el patrimonio cultural.

\section{CONCLUSIONES.}

La difusión digital del patrimonio regional contribuye a promover el desarrollo social, turístico y ambiental de la zona de estudio. La difusión digital del patrimonio cultural es una forma de protegerlo, salvaguardarlo y preservarlo. A su vez, la difusión mediante las tecnologías de la información y la comunicación, debe permitir el acceso virtual del patrimonio a diferentes niveles: acceso a los profesionales interesados, a los especialistas, a los investigadores y al público en general, promoviendo así una intención pedagógica en los productos audiovisuales.

Los saberes locales que hacen parte del patrimonio inmaterial lo constituyen una serie de conocimientos y técnicas tradicionales relacionadas con el hábitat, esas tradiciones están asociadas a la fabricación de objetos artesanales, son técnicas ancestrales, que continúan vigentes y que actualmente tiene una alta demanda, son generadoras de empleo y dinamizadores de la economía local.

Ante las posibilidades que ofrece el lenguaje de los nuevos medios de comunicación e información, la educación y la difusión digital del patrimonio a través del audiovisual sigue siendo una cuestión pendiente. Los audiovisuales realizados con fines educativos por su impacto y amplia divulgación se convierten en herramientas de transmisión viables, pertinentes y de alguna manera necesarias, frente al consumo global de productos visuales y frente a la necesidad de conocer y proteger el patrimonio cultural.

Asimismo, los medios de comunicación permiten promover las tradiciones culturales posibilitando que las comunidades puedan reconocer y valorar sus manifestaciones culturales inmateriales. En este sentido, son las comunidades quienes lo resignifican, lo heredan y le otorgan valor. Es justamente desde la universidad donde se hace posible crear los grupos interdisciplinarios que desarrollen ideas y prototipos para llenar el vacío que hay en difusión digital del patrimonio cultural y propiciar el puente entre el ámbito del patrimonio con la sociedad. 


\section{FUENTES REFERENCIALES.}

APARICI, Roberto, La revolución de los medios audiovisuales: educación y nuevas tecnologías, Madrid, Ediciones de la Torre, 1996.

CASACUBERTA, David, Creación colectiva: en Internet el creador es el público, Barcelona, Gedisa, 2003.

CHOI, Insook, Interactive documentary: A production model for nonfiction multimedia narratives, En: Intelligent technologies for interactive entertainment, Berlin, Springer Verlag, 2009.

DELEUZE, Gilles, La imagen-movimiento, Estudios sobre cine 2, Barcelona, Paidós, 1985.

ECO, Umberto, Lector in Fabula, La cooperación interpretativa en el texto narrativo, Barcelona, Editorial Lumen, 1993.

GAUDENZI, Sandra, Digital Interactive documentary: from representing reality to co-creating reality. Londres, University of Goldsmiths, Centre for Cultural Studies, 2009.

GIANETTI, Claudia, Ars telemática: telecomunicación, Internet y Ciberespacio, Barcelona, I'Angelot, 1998.

GIANNETTI, Claudia, Estética Digital, Sintopía del arte, la ciencia y la tecnología, Barcelona, Associació de Cultura Conteporánia L'Agelot, 2002.

GIFREU, Arnau, El documental interactivo, Barcelona, Editorial UOC, 2013.

JENKINS, H. Transmedia Storytelling. Moving characters from books to films to video games can make them stronger and more compelling, Technology Review. Recuperado de:https://www.technologyreview.com/s/401760/transmedia-storytelling/

MAFFESOLI, Michel. El ritmo de la vida. Variaciones sobre el imaginario posmoderno, México, Siglo XXI Editores, 2012.

MANOVICH, Lev, El lenguaje de los nuevos medios de comunicación, Barcelona, Paidós, 2005.

MORENO, Isidro, Musas y nuevas tecnologías el relato hipermedia, Barcelona, Paidós Comunicaciones, 2002.

MORENO, Isidro, ANDRADE, Vinicius y COLORADO, Arturo ArTecnología, Conocimiento aumentado y accesibilidad, Madrid, Universidad Complutense de Madrid, 2014.

LÉVY, Pierre. Cibercultura. Barcelona, Ed. Anthropos, 2007.

PRADA, Juan Martín, La creatividad de la multitud conectada y el sentido del arte en el contexto de la Web 2.0, en Revista Estudios visuales, ensayo, teoría y crítica de la cultura visual y el arte contemporáneo, Enero 2003.

SCOLARI, Carlos, Hipermediaciones, Elementos para una teoría de la comunicación digital interactiva, Barcelona, Editorial Gedisa, 2008. SCOLARI, Carlos, Narrativas Transmedia, Barcelona, DEUSTO, 2013.

SCOLARI, Carlos, Narrativas Transmedia, Barcelona, DEUSTO, 2013. 
Documental interactivo para la difusión de los saberes y quehaceres del patrimonio cultural

III CONGRESO INTERNACIONAL DE INVESTIGACIÓN EN ARTES VISUALES :: ANIAV 2017 :: GLOCAL [codificar, mediar, transformar, vivir] http://dx.doi.org/10.4995/ANIAV.2017.5275 